\title{
Ethoprophos fate on soil-water interface and effects on non-target terrestrial and aquatic biota under Mediterranean crop-based scenarios
}

\author{
Sara Leitão ${ }^{\mathrm{a}, *}$, Matilde Moreira-Santos ${ }^{\mathrm{b}}$, Paul J. Van den Brink ${ }^{\mathrm{c}, \mathrm{d}}$, Rui Ribeiro ${ }^{\mathrm{b}}$, \\ M. José Cerejeira ${ }^{\mathrm{a}}$, José Paulo Sousa ${ }^{\mathrm{b}}$ \\ ${ }^{a}$ Instituto Superior de Agronomia, University of Lisbon, Centro de Engenharia dos Biossistemas (CEER), Tapada da Ajuda, 1349-017 Lisboa, Portugal \\ b IMAR-CMA, Department of Life Sciences, University of Coimbra, Apartado 3046, 3001-401 Coimbra, Portugal \\ ${ }^{\mathrm{c}}$ Department of Aquatic Ecology and Water Quality Management, Wageningen University, Wageningen University and Research Centre, P.O. Box 47, 6700AA \\ Wageningen, The Netherlands \\ ${ }^{\mathrm{d}}$ Alterra, Wageningen University and Research Centre, P.O. Box 47, 6700AA Wageningen, The Netherlands
}

\section{A R T I C L E I N F O}

\section{Article history:}

Received 26 August 2013

Received in revised form

17 January 2014

Accepted 22 January 2014

Available online 21 February 2014

Keywords:

Ethoprophos

Runoff

Leaching

Soil elutriate

Terrestrial and freshwater ecotoxicology

Natural soil

\begin{abstract}
A B S T R A C T
The present study aimed to assess the environmental fate of the insecticide and nematicide ethoprophos in the soil-water interface following the pesticide application in simulated maize and potato crops under Mediterranean agricultural conditions, particularly of irrigation. Focus was given to the soil-water transfer pathways (leaching and runoff), to the pesticide transport in soil between pesticide application (crop row) and non-application areas (between crop rows), as well as to toxic effects of the various matrices on terrestrial and aquatic biota. A semi-field methodology mimicking a "worst-case" ethoprophos application (twice the recommended dosage for maize and potato crops: $100 \%$ concentration $\mathrm{v} / \mathrm{v}$ ) in agricultural field situations was used, in order to mimic a possible misuse by the farmer under realistic conditions. A rainfall was simulated under a slope of $20^{\circ}$ for both crop-based scenarios. Soil and water samples were collected for the analysis of pesticide residues. Ecotoxicity of soil and aquatic samples was assessed by performing lethal and sublethal bioassays with organisms from different trophic levels: the collembolan Folsomia candida, the earthworm Eisenia andrei and the cladoceran Daphnia magna. Although the majority of ethoprophos sorbed to the soil application area, pesticide concentrations were detected in all water matrices illustrating pesticide transfer pathways of water contamination between environmental compartments. Leaching to groundwater proved to be an important transfer pathway of ethoprophos under both crop-based scenarios, as it resulted in high pesticide concentration in leachates from Maize $\left(130 \mu \mathrm{g} \mathrm{L}^{-1}\right)$ and Potato $\left(630 \mu \mathrm{g} \mathrm{L}^{-1}\right)$ crop scenarios, respectively. Ethoprophos application at the Potato crop scenario caused more toxic effects on terrestrial and aquatic biota than at the Maize scenario at the recommended dosage and lower concentrations. In both cropbased scenarios, ethoprophos moved with the irrigation water flow to the soil between the crop rows where no pesticide was applied, causing toxic effects on terrestrial organisms. The two simulated agricultural cropbased scenarios had the merit to illustrate the importance of transfer pathways of pesticides from soil to groundwater through leaching and from crop rows to the surrounding soil areas in a soil-water interface environment, which is representative for irrigated agricultural crops under Mediterranean conditions.
\end{abstract}

(c) 2014 Elsevier Inc. All rights reserved.

\section{Introduction}

The natural variability of environmental conditions may influence the exposure of non-target organisms to pesticides due to

\footnotetext{
* Corresponding author.

E-mail addresses: saraleitao@isa.utl.pt (S. Leitão), matilde.santos@zoo.uc.pt (M. Moreira-Santos)

Paul.vandenBrink@wur.nl (P.J. Van den Brink), rui.ribeiro@zoo.uc.pt (R. Ribeiro), mcerejeira@isa.utl.pt (M. José Cerejeira),jps@zoo.uc.pt (J.P. Sousa).
}

differences in, among others, climate and soil characteristics (Chelinho et al., 2011; De Silva et al., 2009; Domene et al., 2011). As such, in the new regulation concerning the placing of plant protection products on the market (ECR, 2009), the European Union established three zones (North, Centre and South) in Europe, making exposure scenarios for the environmental risk assessment of pesticides more realistic according to specific edapho-climatic conditions. Under Mediterranean conditions (South), pesticide driven surface water contamination is mainly related to soil erosion and runoff ensuing from rain events 
(Tarazona, 2005). This becomes of great importance when looking at specific contamination pathways of pesticides in the soil-water interface of agricultural fields due to site hydrology, as well as agricultural irrigation and rain (Berenzen et al., 2005). Therefore, the need to study pesticide behaviour under realistic exposure scenarios in Mediterranean conditions is of paramount importance, also due to the scarcity of information on pesticide fate under natural environment and their effects on biota for this region (Daam et al., 2011).

Extrapolating results from laboratory experiments to the field scale under outdoor conditions adds uncertainty to environmental risk assessment (Boesten and Gottesbüren, 2000; Bouraoui, 2007). This has encouraged the use of different methodologies to assess pesticide fate in soil and routes of entry into the aquatic compartment and their effects on the biota. To address this knowledge gap, a semi-field crop-based experiment using a soil-water simulator was performed in the present study. This soil-water simulator was developed in a previous study (Chelinho et al., 2012), and its use under controlled conditions decreases variability in collected data which is often observed in field experiments, while maintaining the natural characteristics of the system under realistic field exposure conditions (e.g. soil type, slope, climatic condition, irrigation). With this approach, the environmental risk of pesticide applications can be assessed for a particular agricultural area in an integrated way, taking into account not only the soil compartment but also specific soil-water transfer pathways such as leaching and runoff and soil elutriates as a measure of soil retention capacity, i.e., the potential of contaminants to be mobilized into aquatic systems through soil (Chelinho et al., 2012).

In the present study, this semi-field methodological approach was applied to simulate the application of the pesticide ethoprophos on two irrigated crops (maize and potato) under a realist "worst-case" of possible misuse by the farmers in a major agricultural area of Central Portugal (Ribatejo) under Mediterranean conditions $\left(39^{\circ} 22^{\prime} 57.79^{\prime \prime} \mathrm{N} 8^{\circ} 32^{\prime} 57.35^{\prime \prime} \mathrm{O}\right)$.

Potential pesticide contamination of water bodies is of paramount importance for this area due to its proximity of the UNESCO biosphere reserve "Paul do Boquilobo", which contains surface waters that are of great importance for bird conservation and biodiversity protection (ICNF, 2013). This reserve is in the vicinity of a hydrogeologically vulnerable area where several pesticides have been detected in surface and ground waters at concentrations that may be expected to lead to environmental side-effects (Silva et al., 2012a, 2012b).

The objectives of the present study were: (i) to assess the fate of ethoprophos in the soil-water interface focusing both on transfer pathways from soil to water compartments through leaching, run-off and soil elutriates and on the mobility within the pesticide application and non-application areas by performing pesticide applications mimicking realistic field conditions; (ii) to assess the pesticide ecotoxicological effects of soil samples from both crops areas (crop row and between rows) to terrestrial biota, by performing reproduction assays with the collembolan Folsomia candida and the earthworm Eisenia andrei, and of the different water matrices (leachates, runoff and soil extracts) to aquatic organisms by performing lethal and sublethal toxicity assays with the standard cladoceran species Daphnia magna; and (iii) to compare and link exposure and ecotoxicological results from soil and water samples, herewith assessing the relative importance of the different soil-water transfer pathways (leaching, runoff and elutriates) for risk assessment of water compartments.

\section{Materials and methods}

An experimental semi-field methodology using natural soil was performed to mimic a crop-based pesticide application under a "worst-case" field scenario.
As "worst-case", an application of twice the recommended dosage established in Portugal for ethoprophos formulated product, as representing a possible misuse by the farmers, was assumed.

\subsection{Pesticide characterization}

The pesticide ethoprophos (CAS 13194-48-4; O-ethyl S,S-dipropyl phosphorodithioate) is registered in Portugal for use as an insecticide in maize crop and as a nematicide in potato crop. Ethoprophos is a broad spectrum organophosphate nematicide and insecticide with moderate residual activity and is not phytotoxic (MacBean, 2012; Karpouzas and Walker, 2000). It acts as an acetylcholinesterase inhibitor and is a non-systemic nematicide and soil insecticide with contact action (MacBean, 2012). It is effective against potato nematodes (Globodera rostochiensis (Wollenweber) Behrens, G. pallide (Stone) Behrens) and should be applied before potato planting. The pesticide is effective against soil insects (Agriotes spp., Agrotis spp. and Melolontha spp.) on maize crop (Karpouzas and Walker, 2000) and is applied at the planting stage. Ethoprophos has high solubility in water (700 $\mathrm{mg} \mathrm{L}^{-1}$; MacBean, 2012) and has potential to volatilize (78 mPa; EFSA, 2006). The organic carbon sorption coefficient indicates that the pesticide sorbs moderately to soil and has a low mobility in water (Kfoc $111 \mathrm{ml} \mathrm{g}^{-1}$; EFSA, 2006). The octanol-water partition coefficient (Log Kow 3.59; MacBean, 2012) indicates bioaccumulation potential (Log Kow > 3; FOOTPRINT, 2012). Ethoprophos (DT50 field 4-25 d for a representative range of soils from southern and central Europe locations; EFSA, 2006) is not persistent in soil (DT50 field $<30 \mathrm{~d}$; EC, 2000), has the potential to leach to groundwater (GUS 2.73) depending on the field conditions $(1.8<$ GUS $<2.8$ : transition; Gustafson, 1989), and according to its Predicted Environmental Distribution (PED soil 76.1\%; PED water 22.1\%; PED air $0.122 \%$; Mackay, 2001) shows a high affinity for the soil compartment (PED $<20 \%$ : very low affinity; $20 \%$ S PED < 40\%: low affinity; $40 \%$ S PED < 60\%: average affinity; $60 \%$ $\leq$ PED $<80 \%$ : high affinity; PED $\geq 80 \%$ : very high affinity; Mackay, 2001). Ethoprophos concentrations in natural waters and soils are not documented. Ethoprophos effects on non-target soil and aquatic organism are not well known and the scarce information available for terrestrial organisms was obtained using artificial soil (EFSA, 2006), although effects on aquatic and terrestrial arthropods may be expected due to the pesticide type of toxic action as an insecticide and nematicide (Frampton et al., 2006; Maltby et al., 2005). In fact, adverse effects of ethoprophos on the abundance and biomass of earthworms are known. Potter et al. (1994) observed a reduction in both endpoints of more than $80 \%$ observed three weeks after the application of $5.6 \mathrm{~kg}$ a.i. $\mathrm{ha}^{-1}$ of Mocap10G in turf soil.

\subsection{Soil-water simulator experimental setup}

A stainless steel transportable soil flume system of $0.4 \mathrm{~m}^{2}$ (from here onward referred to as soil-water simulator - SWS), with a controllable depth (maximum of $100 \times 40 \times 20 \mathrm{~cm}^{3}$; length, width and height, respectively), with two articulated perforated platforms that can move independently allowing to work under different slopes was used (see Chelinho et al. (2012) for additional details). This apparatus allows the collection of soil and water samples and the evaluation of the exposure and the effects on both terrestrial and aquatic compartments. The experimental design followed in the present study consisted of three SWS that were setup in a horizontal position to guarantee the same conditions of pesticide fate in the entire area: one was used as the Control with no pesticide application (Control SWS), and the two others under the established scenarios of ethoprophos applications on maize (Maize SWS) and potato (Potato SWS) crops, respectively.

The natural soil used in the experiment was a sandy clay loam soil from an agricultural area at Ribatejo (Central Portugal) that had never been cultivated. The soil was a Eutric cambisol (EUDASM, 2012) and was tested for the absence of pesticide residues using a multi method ASU L 00.00-34 GC detection analysis (ASU L, 1999), validating its use as reference soil. Prior to the experiment, the uppermost soil layer (top 15-20 cm) was collected and major stones and vegetation were manually removed. The soil was immediately characterized by evaluating its $\mathrm{pH}$ (5.0; $1 \mathrm{M} \mathrm{KCl})($ ISO, 1994), moisture content (5\%), water-holding capacity (35.9\% dry weight; ISO, 1998), organic matter content (5.74\%; dry combustion ISO, 1995) and particle size distribution (54.4\% sand; $22.1 \%$ silt and $23.5 \%$ clay; Hydrometer of Boyoucos, Internal Method) and soil texture (sandy clay loam; Pierzynski et al., 2000). In addition, cation exchange capacity, sum of base exchange, degree of base saturation, and chemical parameters (total elements) were assessed by an independent laboratory (Supplementary Material - Table 1). The soil was air dried and preserved at room temperature till SWSs setup. The experiment was prepared by setting up the SWSs, placing first a 5 - $\mathrm{cm}$ layer of glass beads ( $1 \mathrm{~cm}$ diameter) at the bottom of each of the three SWS platforms to avoid clogging and facilitate leachate percolation. On top of the glass beads, a $15-\mathrm{cm}$ layer of soil was placed up to the edge of the platforms so that the SWS frame would not pose as an obstacle during the runoff event. The soil was left to settle and stabilize its structure for 30 days to become similar to the field soil as much as possible. After this, the soil was prepared with daily irrigation to maintain its moisture, by daily sprinkling $7.1 \mathrm{~L} \mathrm{~m}^{-2}$ of water for 7 days, according to irrigation practices used in that area of Portugal. 
All SWSs setup and the experiment were performed in a greenhouse with natural sun light. Air temperature and humidity were registered daily through the experiment using a $\mathrm{RH} /$ Temp DATA Logger EL-USB-2T, whereas soil $\mathrm{pH}$ and moisture in all SWS were registered before each irrigation with a Kelway Soil Tester (Kelway soil ${ }^{\mathbb{R}}$ acidity and moisture tester Model HB-2).

\subsection{Crop-based simulations}

The experiment started with the insecticide application (day 0 ) at twice the recommended dosage (2RD) for the two crop-based scenarios: Maize SWS and Potato SWS. Ethoprophos was applied directly to the soil as granules (GR) containing $10 \% \mathrm{w} / \mathrm{w}$ active ingredient (a.i.), using the formulated product (f.p.) MOCAP $10 \mathrm{G}^{\mathrm{B}}$ (biological efficacy period of 2-4 months) at 2RD for maize: $25 \mathrm{~kg}$ f.p. ha ${ }^{-1}\left(2.5 \mathrm{~kg}\right.$ a.i. ha $\left.{ }^{-1}\right)$ and potato crop: $200 \mathrm{~kg}$ f.p. ha ${ }^{-1}\left(20 \mathrm{~kg}\right.$ a.i. ha $\left.{ }^{-1}\right)$. In the Maize scenario ethoprophos was applied together with maize grains (FAO600 $P R 33 Y 74$ ), during seeding stage. Individual grains were planted every $17 \mathrm{~cm}$ at $1-\mathrm{cm}$ depth, mimicking field seedling, along a line $(\mathrm{R})$ in the middle of the SWS length, leaving at the sides two areas where no pesticide was applied (BR) (Fig. 1A). Under the potato scenario, no potatoes were placed on the SWS because the pesticide is applied before planting. The Potato SWS area was divided in two equal areas, where the same pesticide dosage was applied, but with different spatial distribution (Fig. 1B). This was performed to attain the volume of soil needed for the terrestrial ecotoxicity assays (i.e., evaluate pesticide effects on soil biota), while maintaining the required soil area to perform the simulation of a runoff event at the end of the experiment by placing the SWS at the requested slope (see below). At the soil sampling area (upper half of the simulator slope positioned during rain event at the end of the experiment), ethoprophos was applied in a strip of $20-\mathrm{cm}$ width $\times 50$-cm length, mimicking crop application row $(R)$, and incorporated into the soil at a depth of $5 \mathrm{~cm}$ by mixing the soil. The remaining area $(20-\mathrm{cm}$ width $\times 50$-cm length) corresponded to the area between crop rows where no pesticide was applied (BR). For the simulation of the rainfall at the lower half of the Potato SWS, ethoprophos was applied on four equidistant points at a depth of $5 \mathrm{~cm}$ and covered with soil in order to allow the pesticide to disperse along the soil column (Fig. 1B).

Pesticide application at both crop-based scenarios took place in the morning, followed by irrigation in all three SWS in late afternoon. Leachates were collected after a waiting period of $30 \mathrm{~min}$. The same irrigation procedure and leachate collection continued daily for the following 9 days after the pesticide application. All leachates were kept separately at $4-6{ }^{\circ} \mathrm{C}$ in glass vials in darkness until used for bioassays and analysis of pesticide residues.

\section{A}

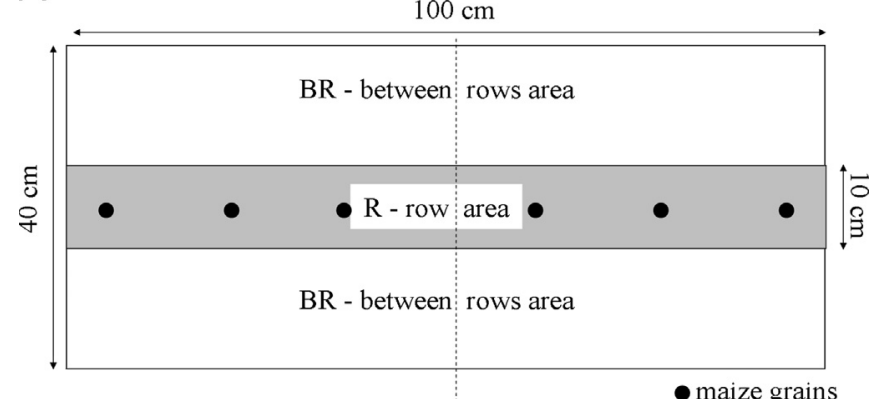

B

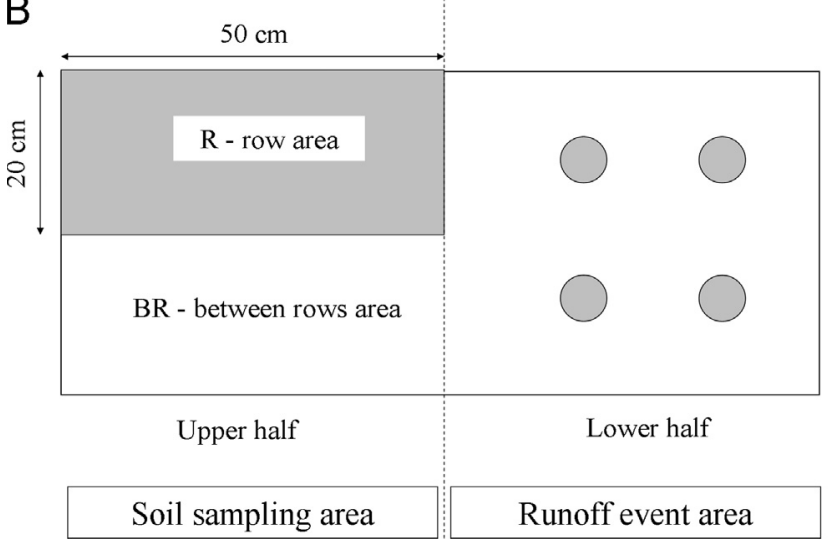

Fig. 1. Spatial scheme of ethoprophos application on Maize (A) and Potato (B) soilwater simulators (SWS). Shadow areas correspond to the pesticide application area.
The experiment ended ten days after the insecticide application with the simulation of a rainfall of $41.6 \mathrm{~L} \mathrm{~m}^{-2}$ to assess potential surface water contamination through runoff. A sprinkler was used under a SWS slope of $20^{\circ}$ to mimic the study site. The value of $41.6 \mathrm{~L} \mathrm{~m}^{-2}$ was in accordance with the highest monthly precipitation during the time when the product must be applied, as observed in the year of 2010 (IM, 2010). To obtain the precipitation value for one day, the monthly precipitation value was divided by three to simulate the rainfall that took place in 2010 in just three days. A stock solution of $1 \mathrm{~L}$ of artificial rain water was prepared according to the Standard Technical Procedure for Terrestrial Model Ecosystems (Sousa et al., 2004), with distilled water and a mixture of nutrients [ $\left(\mathrm{NH}_{4}\right)_{2} \mathrm{SO}_{4}$ $925 \mathrm{mg} ; \mathrm{NaCl}$ - $386 \mathrm{mg}$; $\mathrm{CaCO}_{3}-200 \mathrm{mg} ; \mathrm{MgSO}_{4}-180 \mathrm{mg} ; \mathrm{KCl}-37 \mathrm{mg} ; \mathrm{KH}_{2} \mathrm{PO}_{4}-$ $14 \mathrm{mg} ; \mathrm{NaNO}_{3}-40 \mathrm{mg} ; \mathrm{HNO}_{3}(3.5 \mathrm{M})-2.0 \mathrm{ml}$ and $\mathrm{HCl}(1.0 \mathrm{M})-1.0 \mathrm{ml}$. The rainfall was performed on the lower half of all three SWS (Fig. 1) by isolating the upper half soil with plastic sheets placed in vertical till the glass beads level, so that no water would get in contact with the soil. Runoff waters resulting from the rainfall were kept in glass vials at $4-6{ }^{\circ} \mathrm{C}$ in darkness until used for bioassays and analysis of pesticide residues.

After the rainfall simulation, soil samples from the isolated upper half of all three SWS (Control SWS and R and BR areas for Potato and Maize SWS) were collected from the upper $10-\mathrm{cm}$ soil layer as composite samples for pesticide analysis and ecotoxicity bioassays. Soil samples for pesticide residue analysis were frozen to $-20^{\circ} \mathrm{C}$ until laboratory extraction and analysis through liquid extraction/ cleanup followed by gas chromatography/mass spectrometry (LE/GC-MS), with a limit of quantification (LOQ) of $0.03 \mathrm{mg} \mathrm{kg}^{-1}$ (ASU L, 1999). Soil samples for elutriates and terrestrial ecotoxicity bioassays were kept at $4-6{ }^{\circ} \mathrm{C}$ in darkness for $24 \mathrm{~h}$ until use. Ethoprophos residues were analyzed in all water matrices (leachates, runoff and elutriates from soil at $\mathrm{R}$ and $\mathrm{BR}$ areas) from the two crop-based scenarios through liquid chromatography tandem mass spectrometry (LC-MS/MS) with a LOQ of $0.05 \mu \mathrm{L} \mathrm{L}^{-1}$ (DIN, 1993; ISO, 2000). All pesticide residue analyses in soil and water samples were performed by an independent laboratory.

\subsection{Terrestrial ecotoxicity evaluation}

Terrestrial ecotoxicity assays were performed with collembolan and earthworms, two invertebrate groups that are important for soil functioning (Lavelle and Spain, 2001). Moreover, the species used (Folsomia candida and Eisenia andrei) are widely used to evaluate the effects of different contaminants and used as standard organisms in terrestrial risk assessment (Tiepo et al., 2010; SANCO, 2002). In order to select the species to be used in this experiment, a study to determine the $50 \%$ effect concentration on terrestrial invertebrates using ethoprophos as active ingredient was performed for three standard soil species according to International Guidelines (ISO, 1998, 1999, 2004), using the same natural soil as in the present experiment (Leitão et al., 2014) resulting in the following chronic effect endpoints: Folsomia candida: $28-\mathrm{d} \mathrm{EC}_{50}=0.027 \mathrm{mg}$ a.i. $\mathrm{kg}^{-1} \mathrm{dw}$ soil; Eisenia andrei: 8 -weeks $\mathrm{EC}_{50}=8.3 \mathrm{mg}$ a.i. $\mathrm{kg}^{-1} \mathrm{dw}$ soil and Enchytraeus crypticus: 4 -weeks $\mathrm{EC}_{50}=68.5 \mathrm{mg}$ a. i. $\mathrm{kg}^{-1} \mathrm{dw}$ soil. Taking into account the density of the natural soil $\left(1.25 \mathrm{~g} \mathrm{~cm}^{-3}\right.$ previously calculated) used on both crop-based experiments and the established soil depth of $15 \mathrm{~cm}$ for all SWS (ha $=1875000 \mathrm{~kg}$ dw soil), the expected concentrations of ethoprophos as active ingredient per kg of dry weight (dw) soil after the application of $2 \mathrm{RD}$ for Maize scenario would be $1.34 \mathrm{mg}$ a.i. $\mathrm{kg}^{-1} \mathrm{dw}$ soil $\left(\mathrm{RD}=0.67 \mathrm{mg}\right.$ a.i. $\mathrm{kg}^{-1} \mathrm{dw}$ soil) and $10.6 \mathrm{mg}$ a.i. $\mathrm{kg}^{-1} \mathrm{dw}$ soil $(\mathrm{RD}=5.3 \mathrm{mg}$ a.i. $\mathrm{kg}^{-1} \mathrm{dw}$ soil) for Potato SWS scenario. On the basis of this information the collembolan Folsomia candida and the earthworm Eisenia andrei were selected as test organisms. Sublethal assays with these two species were performed according to the International Guidelines referred above for all soil samples from both cropbased scenarios including soil from crop row (R) and between crop row (BR) areas at $2 \mathrm{RD}(100 \%(\mathrm{v} / \mathrm{v}))$. Four replicates were used in each of the $F$. candida and $E$. andrei assays. To assess the effect of the recommended dosage (RD) on soil biota, a concentration of $50 \%(\mathrm{v} / \mathrm{v})$ was attained by mixing soil from Maize and Potato SWS $(100 \%$ (v/v) concentration) with soil from the Control SWS in a 50:50 ratio, for each crop-based scenario. The ecotoxicological assays controls were performed using natural soil from the Control SWS where no pesticide was applied. Collembolan and earthworm reproduction inhibition was accounted for in juvenile numbers after 4 and 8 weeks test duration, respectively. Collembolan adults were registered and adult earthworm biomass was also measured after four weeks of exposure. Bioassays results were analyzed using one-way analysis of variance (ANOVA) to assess effects among the two study areas (R and BR) compared to the Control for each SWS crop scenarios (Potato and Maize) and for the $50 \%$ and $100 \%(\mathrm{v} / \mathrm{v})$ concentrations which mimic the RD and $2 \mathrm{RD}$, respectively. The assumptions of normality and homogeneity of variance were checked using Shapiro-Wilkinson and Bartlett's test, respectively. Post-hoc comparisons (Dunnett's test) were applied to verify the existence of significant differences from the Control.

\subsection{Water samples and aquatic ecotoxicity evaluation}

Three kinds of water samples were used for the ecotoxicity evaluation toward aquatic organisms. At the end of the experiment, a leachate composite sample representative of each SWS (Control, Maize and Potato) was prepared by mixing the leachates collected each day. The latter were left to settle at $4{ }^{\circ} \mathrm{C}$ and then 
decanted so that only a representative sample of the soluble fraction of the pesticide was used. Runoff water samples collected after the simulated rain (day 10) were centrifuged ( $20 \mathrm{~min}$ at $2422 \times g$ ) at room temperature for suspended solids removal so that they would not interfere with the cladoceran feeding (Friberg-Jensen et al., 2010). The supernatant was collected and deep frozen at $-20^{\circ} \mathrm{C}$ to inhibit bacterial growth until used (Gao et al., 2006). To evaluate the toxicity toward aquatic organisms of the pesticide water soluble components in the soil pore water, elutriates from $\mathrm{R}$ and BR soil areas of the crop-base scenarios and of the Control SWS were prepared according to DIN 38 414-S4 (1984). For this, a mixture of soil and ASTM reconstituted hard water (1:10 ratio, w/v, based on soil dry weight; OECD, 1998) was shaken in a magnetic stirrer during $24 \mathrm{~h}$, centrifuged as described above and the supernatant collected as elutriate and stored at $4{ }^{\circ} \mathrm{C}$ in the dark until use.

All aquatic assays were conducted on the single leachate and runoff sample originated from each SWS (Control, Maize and Potato), on one elutriate sample from the Control SWS and two elutriate samples from each of the two pesticide SWS scenarios (Maize and Potato), prepared from the R and BR soils, as described above. Aquatic assays were conducted with the cladoceran Daphnia magna, a standard organism used in aquatic risk assessment. All water samples from the three SWS treatments (Control, Maize and Potato) were tested at least at $100 \%(\mathrm{v} / \mathrm{v})$ and $50 \%(\mathrm{v} / \mathrm{v})$ concentrations as an estimate for the potential effect that could be expected at the $2 \mathrm{RD}$ and $\mathrm{RD}$ of the insecticide, respectively, and also at $25 \%$ (mimicking $1 / 2 \mathrm{RD}$ ) to increase the likelihood of discriminating toxic effects between the two crops. This procedure was also adopted for the Control SWS to discriminate other potential stress factors associated to the matrix, from those resulting from the pesticide application (e.g. turbidity).

Lethal assays were performed by determining the inhibition of the mobility of D. magna exposed for $48 \mathrm{~h}$ according to the Daphtoxkit FTM Magna (2000) protocol using the following gradient concentration range for each type of water sample: $6.25 ; 12.5 ; 25 ; 50(\mathrm{RD})$ and $100 \%(\mathrm{v} / \mathrm{v})(2 \mathrm{RD})$. Additionally, a standard test Control was performed with standard growth medium according to the protocol for test validity assessment (Daphtoxkit FтM Magna, 2000). Test organisms were incubated at $19-21^{\circ} \mathrm{C}$ with a $14: 10$-h light:dark cycle, no food was provided and no medium renewal was performed. Lethal results were analyzed for percentage of effect and, if possible, $\mathrm{LC}_{50}$ and $95 \%$ confidence intervals were calculated according to ISO 6341 (2012) and using the Trimmed Spearman-Karber method (Hamilton et al., 1977).

To assess ethoprophos sublethal effects, a 21-days D. magna reproduction assay was performed for each water sample, which consisted of a standard Control plus the $100 \%, 50 \%$ and $25 \%(\mathrm{v} / \mathrm{v})$ concentrations, according to the OECD guidelines (OECD, 1998). A standard test Control was also performed with standard growth medium according to the guidelines for test validity assessment (OECD, 1998). For each treatment, ten replicates, each containing $50 \mathrm{~mL}$ of test solution and one neonate less than $24 \mathrm{~h}$ old were used, which were incubated at $19-21^{\circ} \mathrm{C}$ with a 14-h:10-h light:dark cycle and organisms were fed daily with an algae suspension. Because of the severe lethal effects that occurred after an exposure period as short as $72 \mathrm{~h}$, the only test endpoint possible to evaluate under the conditions established for a sublethal assay was mortality. Survival results were evaluated by one-tailed Fisher's exact test (Microsoft Office Excel) for significant differences $(p<0.05)$ in mortality between the Control SWS and the respective pesticide concentrations (2RD, RD and 1/2RD).

\section{Results and discussion}

\subsection{Air and soil measurements}

Indoor air temperature during the experiment was $17.8 \pm 3.3{ }^{\circ} \mathrm{C}$ and relative humidity was $70.6 \pm 10.5 \%$ (mean values \pm standard deviation). Daily soil $\mathrm{pH}$ and moisture measurements (\% relative saturation) on each of the SWS are presented in Table 1.

\subsection{Ethoprophos fate in soil and water samples}

Ten days after ethoprophos application in the crop-based "worst-case" scenario and daily irrigation, only soil from the row area $(\mathrm{R})$ of Potato SWS scenario showed pesticide residues above the LOQ at $10.5 \mathrm{mg}$ a.i. $\mathrm{kg}^{-1} \mathrm{dw}$ soil (Table 1 ). These observed results in the potato scenario are in agreement with the predicted environmental fate distribution showing a high affinity to the soil compartment (see Section 2.1). In fact, this residue concentration corresponds to $99.1 \%$ of the expected concentration in soil after one application of 2RD for potato crop (10.6 mg a.i. $\mathrm{kg}^{-1} \mathrm{dw}$ soil). At the Maize scenario no pesticide residue was detected in soil possibly due to the dosage against soil insects being ten times lower than that for potato nematodes (see Section 2.3) and also
Table 1

Soil $\mathrm{pH}$ and moisture (mean + standard deviation; $n=10$ ) during the soil-water simulator (SWS) experiment and ethoprophos concentrations in soil and water samples collected at the end of the experiment.

\begin{tabular}{|c|c|c|c|}
\hline & Control & Maize crop & Potato crop \\
\hline \multicolumn{4}{|l|}{ Soil } \\
\hline $\mathrm{pH}$ & $6.3 \pm 0.2$ & $6.3 \pm 0.2$ & $6.1 \pm 0.2$ \\
\hline $\begin{array}{l}\text { Moisture } \\
\quad \text { (\% relative saturation) }\end{array}$ & $63 \pm 27.5$ & $58.5 \pm 20$ & $83 \pm 14.8$ \\
\hline $\begin{array}{l}\text { Pesticide in soil } \\
\qquad\left(\mathrm{mg} \text { a.i. } \mathrm{kg}^{-1} \mathrm{dw} \text { soil }\right)\end{array}$ & n.m & $\mathrm{R}<\mathrm{LOQ}, \mathrm{BR}<\mathrm{LOQ}$ & $\mathrm{R}=10.5, \mathrm{BR}<\mathrm{LOQ}$ \\
\hline \multicolumn{4}{|l|}{ Pesticide in water $\left(\mu \mathrm{g} \mathrm{L}^{-1}\right)$} \\
\hline Leachate & n.m & 130 & 630 \\
\hline Runoff & n.m & 44 & 19 \\
\hline Elutriate & n.m & $\mathrm{R}=130, \mathrm{BR}=6.7$ & $\mathrm{R}=2200, \mathrm{BR}=21$ \\
\hline
\end{tabular}

n.m. - not measured; $\mathrm{R}$ - row area; $\mathrm{BR}$ - between rows area; $\mathrm{LOQ}=0.03 \mathrm{mg} \mathrm{kg}^{-1}$.

due to ethoprophos high solubility in water and low soil sorption (see Section 2.1). This strong soil sorption behaviour observed in the present study with a sandy clay loam natural soil has also been documented for sandy loam soils (Dowling et al., 1994; Smelt et al., 1977) and sandy soils (Boesten and Van der Pas, 2000; Bouraoui, 2007). Under field conditions, ethoprophos dissipated with a DT50 of $28 \mathrm{~d}$ in studies using the same formulated product and recommended dosage as the present study in a sandy loam soil (Boesten and Van der Pas, 2000). A similar DT50 of $22 \mathrm{~d}$ was also observed in a natural sandy soil and losses were attributed mainly to volatilization (Boesten and Van der Pas, 2000; Tiktak, 2000) since ethoprophos has potential to volatilize (see Section 2.1).

Taking into account the observed ethoprophos fate results in soil at the potato scenario, movements to the water compartment would not be likely to occur (Smelt et al., 1977; Tiktak, 2000). However, ethoprophos residues were detected in all water samples from both crop-based scenarios. This movement to the water compartment may be explained by the insecticide physicochemical characteristics and GUS value showing a possible potential for leaching (see Section 2.1). Elutriates from the soil pesticide application area $(\mathrm{R})$ showed the highest ethoprophos concentrations $\left(130 \mu \mathrm{g} \mathrm{L}^{-1}\right.$ for Maize and $2200 \mu \mathrm{g} \mathrm{L} \mathrm{L}^{-1}$ Potato SWS scenarios) followed by leachates and finally the runoff with values of 44 for Maize and $19 \mu \mathrm{g} \mathrm{L}^{-1}$ for the Potato SWS scenarios (Table 1). Ethoprophos was also detected in elutriates from BR area soil of both crops where no pesticide was applied (Table 1), which indicates that the insecticide moved away from where it was applied to the surrounding area. These observed higher values of ethoprophos concentration in leachates than in runoff waters at both crop-based scenarios showing a leaching capacity to groundwater, have also been described in studies on arable fields in Italy also under Mediterranean conditions (Garratt et al., 2002). Ethoprophos degradation in water under natural environmental conditions is not likely to occur given that no chemical hydrolysis $\left(\right.$ DT50 water $>365$ days at $25^{\circ} \mathrm{C}$ and $\mathrm{pH} 7$ ) or photodegradation (stable to photolytic breakdown) are expected (EFSA, 2006).

Environmental fate models have only been predicting the strong sorption behaviour of ethoprophos in soil, not considering other factors that may influence this behaviour, such as water flows (e.g. irrigation), while pesticide leaching models tend to indicate that the leaching potential of ethoprophos is negligible (Garratt et al., 2002; Pistocchi, 2010; Tiktak, 2000). By combining the current fate results of ethoprophos in soil (strong adsorption) and water (leaching potential), the present study emphasizes the need to use different methodologies (semi-field) to better illustrate realistic pesticide contamination pathways and validate pesticide fate and behaviour between several environmental compartments, namely soil and water compartment. 

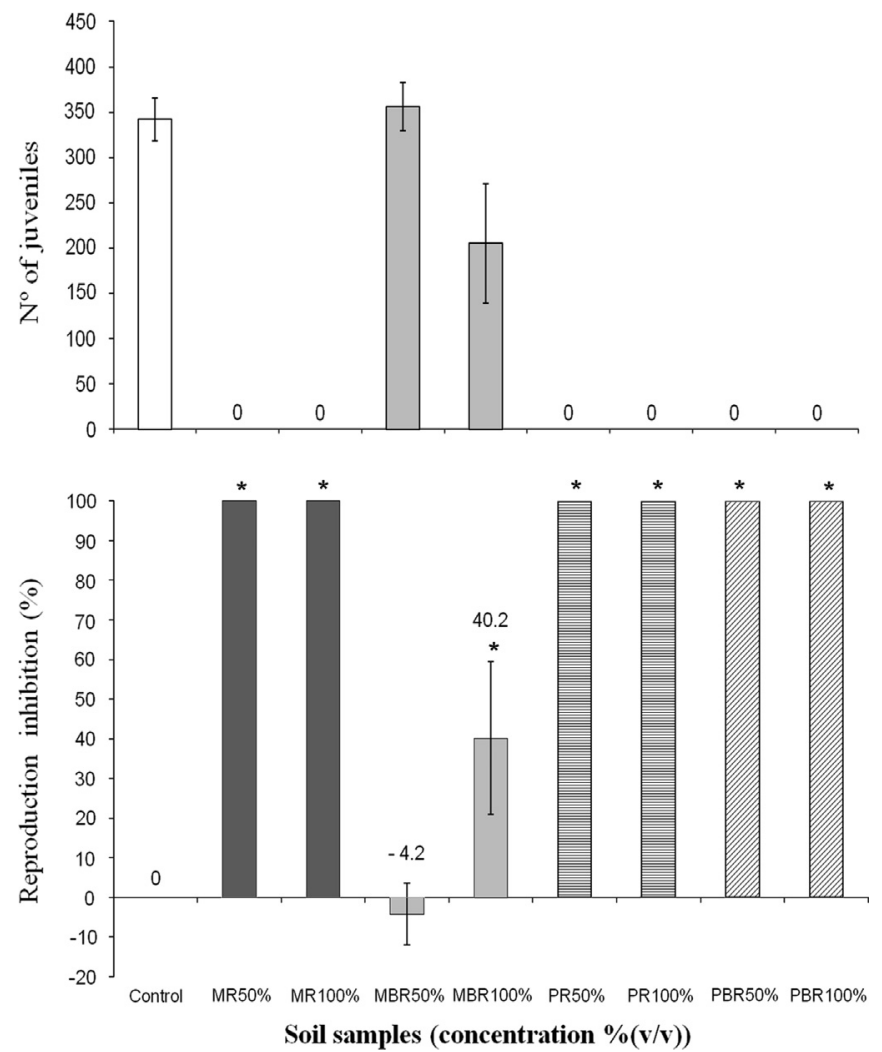

Fig. 2. Effects of ethoprophos (mean values and standard deviation) on the reproduction (number of juveniles and reproduction inhibition) of collembolan exposed to soil from row area (R) and soil from between row (BR) from Maize (M) and Potato (P) scenarios. 50\% - RD and 100\% - 2RD (see details in the text); *Significant differences from control $(p<0.05)$.

\subsection{Linking exposure and effects on biota and evaluation of potential environmental risk}

All terrestrial and aquatic assays proved to be valid according to the respective test validity criteria as recommended in the respective ISO guidelines and protocols described above (see Sections 2.4 and 2.5).

In the aquatic lethal assays, leachate from the 100\% Control SWS caused low mortality of $15 \%$ as well as elutriate with $5 \%$. However, runoff samples from Control SWS caused 40\% lethality at the $100 \%$ concentration, while the $50 \%$ Control SWS concentration caused a low mortality of $5 \%$. Therefore, for leachates and elutriates the Control SWS results, rather than the assay standard Control with reconstituted artificial medium, were used to calculate the lethal toxicity parameters. Runoff samples from both cropbased scenarios were only assessed for the concentration gradient of $6.25-50 \%$ due to the high mortality observed with the Control SWS runoff (which would preclude discriminating effects due to the pesticide from other effects associated to the runoff). At the aquatic 72-h exposure assay under the conditions of a sublethal assay, the Control SWS leachate and runoff samples caused a lethal effect after 48 and $72 \mathrm{~h}$ at the 100\% concentration (50\% and 90\% mortality, respectively, for leachates and $100 \%$ mortality after 48 -h exposure for runoff). Therefore, effects due to the pesticides via leachate and runoff can only be evaluated after $24 \mathrm{~h}$ for all concentrations and up to $72 \mathrm{~h}$ for all (25\% and 50\%) except the $100 \%$ concentration. On the contrary, no mortality was registered for the Control SWS elutriates, and thus effects due to the pesticides via elutriates were assessed for all three concentrations up to 72-h exposure.
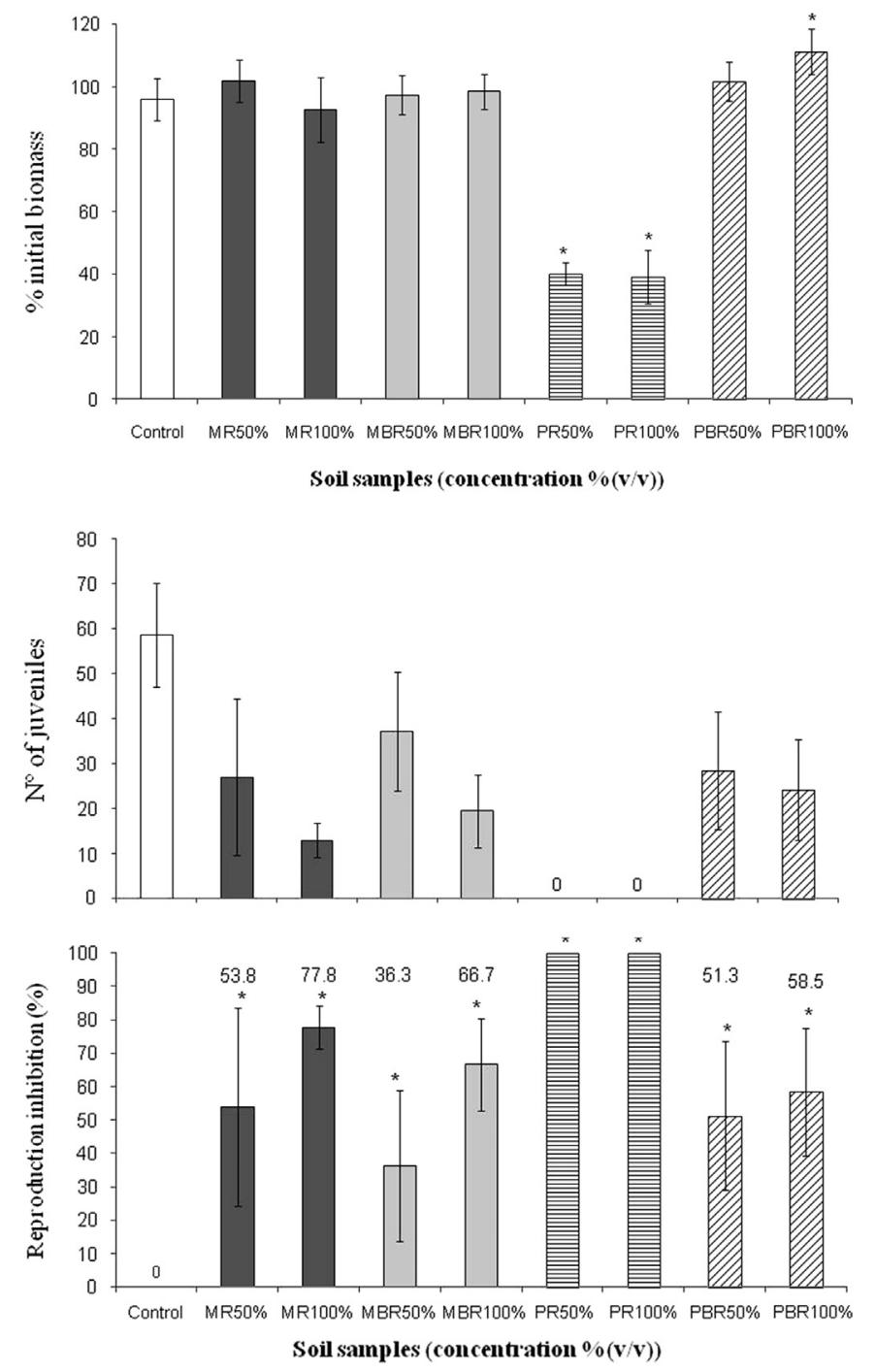

Fig. 3. Initial biomass variation (mean values and standard deviation) of adult Eisenia andrei after four weeks and effects of ethoprophos on the reproduction (number of juveniles and reproduction inhibition) of earthworms exposed to soil from row area (R) and soil from between row (BR) from both Maize (M) and Potato (P) scenarios. 50\% - RD and 100\% - 2RD (see details in the text); *Significant differences from control $(p<0.05)$.

\subsubsection{Maize crop scenario - terrestrial biota and soil compartment}

Although no pesticide residues were detected above the limit of quantification ( $\mathrm{LOQ}=0.03 \mathrm{mg} \mathrm{kg}^{-1}$ ) in any soil sample from the maize crop-based scenario simulation (Table 1), significant effects on non-target terrestrial organisms were observed. The soil collected at crop row area (R) where the pesticide was applied, caused significant effects on collembolans reproduction (1-way ANOVA: $F_{8,27}=155.4, p<0.001$; Dunnett's test: $\left.p<0.05\right)$, with a $100 \%$ mortality of adults and consequently with no offspring at the assumed recommended dosage (RD) and 2RD (50\% and 100\% concentrations, respectively; Fig. 2). Earthworm reproduction was also significantly inhibited (1-way ANOVA: $F_{8,27}=12.3$, $p<0.001$; Dunnett's test: $p<0.05$ ) in soil from $\mathrm{R}$ area at both tested concentrations mimicking the RD and 2RD (Fig. 3). Although there is a lack of information on effects of ethoprophos on non-target terrestrial species, these results are in agreement with the previously calculated ethoprophos $\mathrm{EC}_{50}$ of $0.027 \mathrm{mg}$ a.i. $\mathrm{kg}^{-1} \mathrm{dw}$ soil for collembolan using the same natural soil (see Section 2.4), given that this $\mathrm{EC}_{50}$ value is similar to the LOQ of $0.03 \mathrm{mg}$ a.i. $\mathrm{kg}^{-1} \mathrm{dw}$ soil. For earthworms, the previously reported values of $\mathrm{EC}_{50}=8.3 \mathrm{mg} \mathrm{kg}^{-1} \mathrm{dw}$ soil (see Section 2.4), 
Table 2

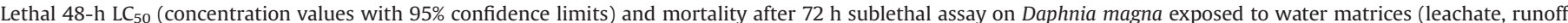

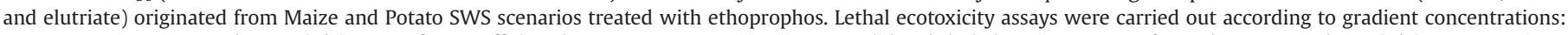

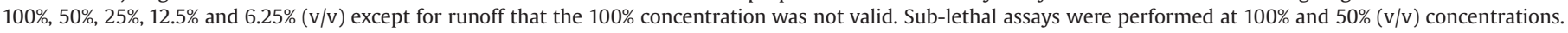

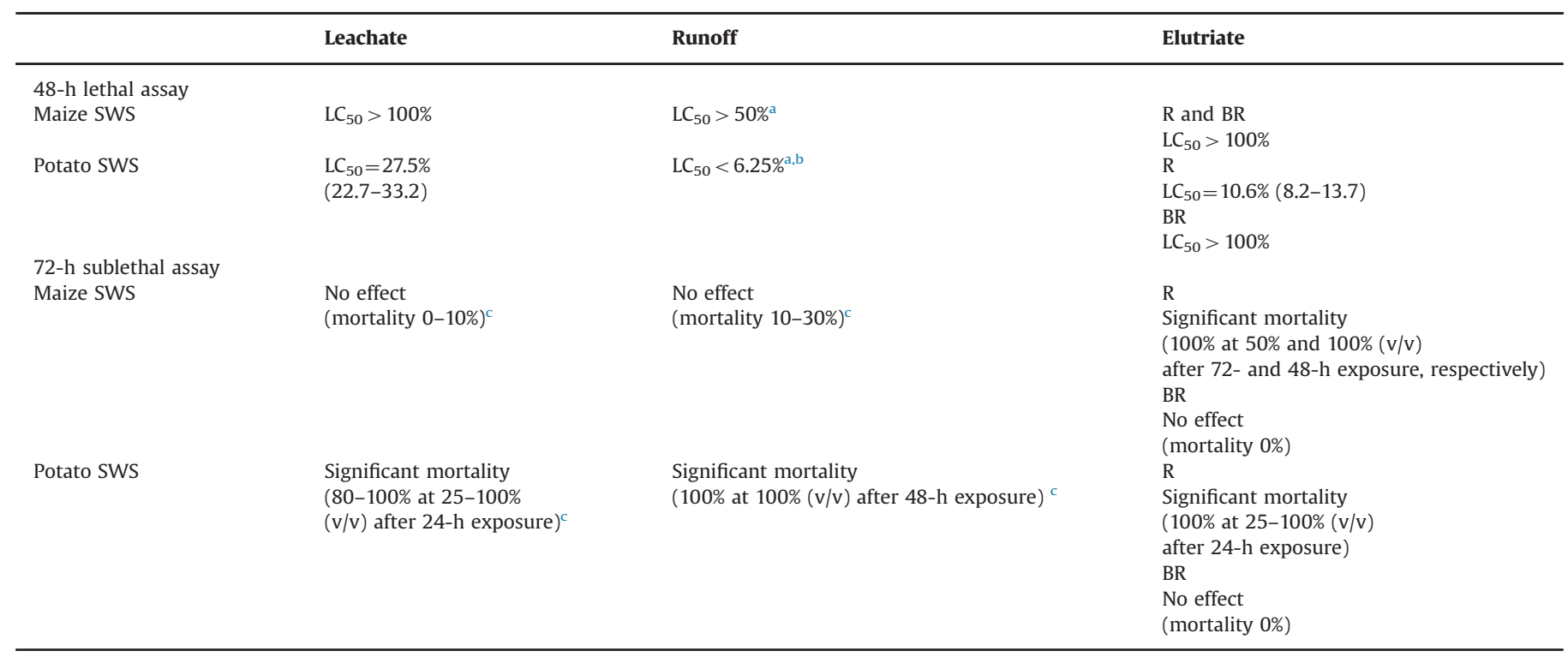

$\mathrm{R}$ - row; BR - between row.

a No effect, a maximum of $5 \%$ effect at $50 \%$ concentration.

b $100 \%$ effect at all concentrations.

${ }^{c}$ Due to elevated mortality in Control SWS, pesticide effects could only be evaluated after $24 \mathrm{~h}$ for all concentrations and up to $72 \mathrm{~h}$ for the $25 \%$ and $50 \%$ concentrations.

14-d $\mathrm{LC}_{50}=39.6 \mathrm{mg} \mathrm{kg}^{-1} \mathrm{dw}$ soil and the 56 -d NOEC value of $<1.67 \mathrm{mg} \mathrm{kg}^{-1} \mathrm{dw}$ soil (EFSA, 2006), with the same formulated product, are higher than the measured concentration of ethoprophos $\left(<0.03 \mathrm{mg} \mathrm{kg}^{-1}\right.$ ), suggesting that the observed pesticide toxicity to earthworms may have been influenced by the characteristics of natural soil and of realistic environmental conditions (EFSA, 2009; Lanno et al., 2004).

Soil from the BR area showed significant effects (1-way ANOVA: $F_{8,27}=67.1, p<0.001$; Dunnett's test: $\left.p<0.05\right)$ at the $100 \%$ concentration corresponding to the applied 2RD on adult collembolan survival (30\% mortality) and number of juveniles (40\% inhibition) (MBR100\%, Fig. 2). However, no significant effects on collembolan reproduction were observed at the $\mathrm{RD}$ ( $50 \%$ concentration), with a small increase of juveniles relatively to the control being observed (Fig. 2). Significant negative effects were also observed on earthworm reproduction (1-way ANOVA: $F_{8,27}=12.3, p<0.001$; Dunnett's test: $p<0.05$ ) in soil from BR area at both concentrations tested (Fig. 3). Adult earthworms biomass after four weeks exposure to soil from both areas ( $R$ and BR, Fig. 3) was not significantly different from the control (Dunnett's test: $p>0.05$ ). Even though ethoprophos is most probably redistributed more strongly in the vertical direction rather than in the horizontal direction (Smelt et al., 1977), when using the same formulations as the present study, the fact that significant effects on collembolan and earthworms, at 2RD and assumed RD, were observed in the area where no pesticide was applied, indicates that the pesticide also moved horizontally from the applied area to the surroundings due to water flows caused by irrigation (Berenzen et al., 2005; Garratt et al., 2002).

As mentioned above, significant effects on the tested organisms were observed, although no pesticide residues were detected in soil. Other stressors that may have influenced the observed toxicity are factors associated to the use of formulated product itself and metabolites. However, the formulated product used (MOCAP $10 G^{\mathbb{R}}$ ) does not have any other toxic additional components than the active ingredient itself (Certis, 2011) and ethoprophos does not degrade in soil in any environmental relevant metabolites (EFSA, 2006). Only a minor metabolite is identified (O-ethyl-S-propylphosphorothioic acid - AE 0592496) that degrades into $\mathrm{CO}_{2}$ and un-extractable residues as final degradation products (EFSA, 2006), and for which there is a lack of information on environmental toxicity.

\subsubsection{Maize crop scenario- aquatic biota and water compartment}

The absence of toxicity towards $D$. magna of leachate waters simulating a groundwater contamination pathway (Table 2), at the assumed 1/2RD and RD after 48- and 72-h (one-tailed Fisher's exact test: $p>0.15$ ) exposure and at 2RD after 48-h exposure (a maximum of $40 \%$ immobilization was observed) is in agreement with the reported value of $48-\mathrm{h} \mathrm{LC}_{50}=200 \mu \mathrm{g} \mathrm{L}^{-1}$ for $D$. magna (EFSA, 2006), given that the latter is higher than the pesticide concentration of $130 \mu \mathrm{g} \mathrm{L}^{-1}$ (Table 1) measured in the present study. The same situation occurred with runoff waters simulating surface water contamination pathway, which after 48- and 72-h (one-tailed Fisher's exact test: $p>0.15$ ) exposure at the assumed RD did not cause significant lethality and for which the measured concentration of ethoprophos in water was lower $\left(44 \mu \mathrm{g} \mathrm{L}^{-1}\right)$ than that of the leachate (Table 1). Unexpectedly, runoff resulting from the Control SWS scenario caused high mortality of $D$. magna in the 48 and 72 -h exposure assays at the $100 \%$ concentration simulating the 2RD (see Section 3.3). However, given that Control SWS elutriate samples were also prepared by centrifugation to remove excess suspended soil particles and showed negligible mortality (see Section 3.3), a negative effect due to the suspended solids originated from the natural soil towards $D$. magna may be dismissed as the cause of this additional stress (Friberg-Jensen et al., 2010). Possibly, the deep freezing of the runoff samples for approximately one week was not enough to control the presence of bacteria and fungi originated mainly from the top soil and thus expected in higher amounts in runoff than in elutriates or leachates (Gao et al., 2006). 
Toxicity towards aquatic life with elutriates from soil in $\mathrm{R}$ area where ethoprophos was applied and between these areas (BR; Table 2) differed from the terrestrial toxicity results, where both areas proved to be toxic for collembolan and earthworms reproduction (see Section 3.3.1). No effects on D. magna were observed with elutriates from the BR area soil after 48- and 72-h exposure at all tested concentrations as expected (Table 2), since this water sample showed the lowest pesticide concentration $\left(6.7 \mu \mathrm{g} \mathrm{L}^{-1}\right)$ among all water samples. In spite of no observed toxicity after $24 \mathrm{~h}$ of exposure with elutriates from the $\mathrm{R}$ area, a significant toxicity towards aquatic life was observed after 48- and 72-h of exposure (one-tailed Fisher's exact test: $p<0.001$ ) at concentrations corresponding to the assumed 2RD and both RD and 2RD (Table 2), most likely due to the longer exposure period.

These results illustrate the importance of studying combined environmental compartments to increase ecological realisms in risk assessment evaluations on soil-water interface environments, as well as to evaluate the potential of contaminants to be mobilized into aquatic systems from the soil compartment.

\subsubsection{Potato crop scenario - terrestrial biota soil compartment}

After the application of ethoprophos at 2RD and daily irrigation during 10 days, the soil from the pesticide application area (R) caused $100 \%$ mortality of adult collembolans (1-way ANOVA: $F_{8,27}=155.4, p<0.001$; Dunnett's test: $\left.p<0.05\right)$, and significant effects on adult earthworms survival (1-way ANOVA: $F_{8,27}=53.8$, $p<0.001$ ) originating no offspring at both concentrations tested (PR100\% - 2RD and PR50\% - RD, Figs. 2 and 3). The remaining adults showed a significant decrease of initial biomass (1-way ANOVA: $\left.F_{8,27}=58.7, p<0.001\right)$ of approximately $60 \%$ at both concentrations (R50\% and R100\%; Fig. 3).

The same high toxicity results were observed at both tested concentrations for collembolan reproduction in soil from BR areas where no pesticide was applied. Significant negative effects on adult earthworm reproduction for the same soil area (1-way ANOVA: $F_{8,27}=12.3, p<0.001$ ) were also observed with only an average of 20-30 juveniles at both concentrations versus the 59 juveniles in the Control SWS soil (Fig. 3). These negative effects on earthworm reproduction are in agreement with the previously reported $\mathrm{EC}_{50}$ of $8.3 \mathrm{mg} \mathrm{kg}^{-1} \mathrm{dw}$ soil (see Section 2.4). In spite of no pesticide residues were detected in soil from BR area (Table 1), its detection in elutriates may illustrate the availability of ethoprophos to terrestrial invertebrates through the soil pore water which is the main uptake source for these organisms (EFSA, 2009; Styrishave et al., 2008), given that elutriates can be a measure of the soil retention function, i.e., on the potential of contaminants to move to the water compartment. The observed negative impact on collembolan from soil from the $\mathrm{R}$ and $\mathrm{BR}$ area are in agreement with the previously calculated ethoprophos $\mathrm{EC}_{50}$ of $0.027 \mathrm{mg}$ $\mathrm{kg}^{-1} \mathrm{dw}$ soil (see Section 2.4), a value much lower than the measured concentration of $10.5 \mathrm{mg}$ a.i. $\mathrm{kg}^{-1} \mathrm{dw}$ soil in $\mathrm{R}$ area and the limit of quantification of $0.03 \mathrm{mg}$ a.i. $\mathrm{kg}^{-1} \mathrm{dw}$ soil for the BR area (Table 1).

In terms of lethal toxicity to adult earthworms after 4-weeks exposure to soil from $\mathrm{R}$ area, the mortality effects of $68 \%$ and $25 \%$ at $2 \mathrm{RD}$ and the assumed $\mathrm{RD}(100 \%$ and $50 \%$ concentrations, respectively) were observed at lower concentrations (10.5 mg a.i. $\mathrm{kg}^{-1} \mathrm{dw}$ soil at the $100 \%$ concentration) than the reference value using the same formulated product (14-d LC $50=39.6 \mathrm{mg} \mathrm{kg}^{-1} \mathrm{dw}$ soil; EFSA, 2006). This may suggest that the natural soil properties and the mimicking of realistic environmental conditions of the experiment may have influenced the pesticide toxicity towards the tested organisms (EFSA, 2009; Lanno et al., 2004), as well as chronic toxicity processes per se since the reference value was attained at a minor duration (14 days) than the present study assay (28 days).

At the soil area where no pesticide was applied (BR), adult earthworms survival was not significantly affected at RD and 2RD, as well as their initial biomass (Dunnett test $p=0.995$ ) (Fig. 3). Furthermore, a significant increase of initial biomass was observed at $100 \%$ concentration corresponding to the 2 RD (PBR100\%; Fig. 3 ). Other author has registered this positive effect on the earthworm biomass when studying short-term toxicity endpoints, such as survival that depends on dermal uptake, when exposed to organophosphates (De Silva et al., 2009). Although classifying effects of pesticides within the same chemical group must be done with special attention to the pesticide individual performance and to the biology of the organism (Wang et al., 2012), in the present study the low ethoprophos concentration in natural soil $\left(<\mathrm{LOQ}=0.03 \mathrm{mg} \mathrm{kg}^{-1}\right.$ ) may have led to enhanced food intake of earthworms resulting in biomass increase (Fig. 3).

Soil from the $\mathrm{R}$ area proved to be more toxic for earthworm reproduction than the surrounding area (BR) and no evident differences were observed between the $50 \%$ and $100 \%$ concentrations, which mimic RD and $2 \mathrm{RD}$, respectively (Fig. 3).

\subsubsection{Potato crop scenario - aquatic biota and water compartment}

In spite of ethoprophos strong adsorption to soil particles, the soluble fraction component of the pesticide moved to the water compartment through leaching and runoff as well as elutriates (Table 1), illustrating the potential of the pesticide to be mobilized into the aquatic systems.

Leachate waters caused high toxicity to $D$. magna after the 48-h exposure assay with an $\mathrm{LC}_{50}$ of $27.5 \%$ (Table 2). Taking into consideration the measured pesticide concentration of $630 \mu \mathrm{g} \mathrm{L}^{-1}$ (Table 1) in leachate waters at the $100 \%$ concentration resulting from the application of $2 \mathrm{RD}$, the observed $48-\mathrm{h} \mathrm{LC}_{50}$ of $27.5 \%$ may correspond to an $48-\mathrm{h} \mathrm{LC}_{50}$ value of $173 \mu \mathrm{g} \mathrm{L}^{-1}$ (143$\left.209 \mu \mathrm{g} \mathrm{L}^{-1}\right)$. This ecotoxicity value is in agreement with the documented $48-\mathrm{h} \mathrm{EC}_{50}$ of $200 \mu \mathrm{g} \mathrm{L}^{-1}$ for D. magna (EFSA, 2006).

Nevertheless, the observed high toxicity of leachates ( $>80 \%$ mortality) towards the cladoceran during the 72-h sublethal assay (Table 2; after 24-h exposure at all concentrations and after 72-h exposure at $25 \%$ and $50 \%$ concentrations; one-tailed Fisher's exact test: $p<0.0004)$ corresponds to concentrations simulating the application of $1 / 2 \mathrm{RD}, \mathrm{RD}$ and $2 \mathrm{RD}$ showing the potential risk of groundwater contamination under the simulated realistic scenario for potato crop using the nematicide ethoprophos.

The application of the tested formulation (granules at 2RD $20 \mathrm{~kg}$ a.i. $\mathrm{ha}^{-1}$ ) can result in a quite persistent presence of ethoprophos in water (Robinson et al., 1999) and as such, pose a threat to aquatic life namely microcrustaceans that occupy an important position in food webs (Gustafsson et al., 2010; Warming et al., 2009). The observed high lethal effects ( $100 \%$ mortality) towards D. magna after the 48-h and 72-h exposure assays (one-tailed Fisher's exact test: $p<0.001$ ) with runoff waters at the simulated 2RD (100\% concentration) and less (Table 2) was not expected, since the documented $48-\mathrm{h} \mathrm{EC}_{50}$ of $200 \mu \mathrm{g} \mathrm{L}^{-1}$ for D. magna (EFSA, 2006) is much higher than the measured ethoprophos concentration in water of $19 \mu \mathrm{g} \mathrm{L}^{-1}$. Other stressors than those involved directly with the pesticide use, such as freezing procedures related to sample treatment prior to the bioassays performance may have influenced the observed ecotoxicological response, as discussed for the Maize scenario (see Section 3.3.2). However, a toxic response was observed and as such, runoff after the rainfall as a surface waters contamination pathway simulated at the potato based exposure realistic "worst-case" scenario with the application of ethoprophos may possibly cause negative effects towards the aquatic communities. 
Taking into account the soil retention function through the aqueous extract (elutriates) where the soluble components of the pesticide are present, aquatic toxicity results (Table 2 ) differ from terrestrial results where both areas ( $R$ and $B R$ ) revealed to be toxic for collembolan and earthworms populations (see Section 3.3.3). Only elutriates from soil $\mathrm{R}$ area showed high aquatic toxicity after 48- and 72 -h exposure (48-h $\mathrm{LC}_{50}=10.6 \%$ and $100 \%$ mortality, onetailed Fisher's exact test: $p<0.001$, respectively), while no effects on D. magna were observed on elutriate from BR soil area where no pesticide was applied (Table 2). Although ethoprophos residues were quantified at elutriates from BR area soil $\left(21 \mu \mathrm{g} \mathrm{L}^{-1}\right.$, Table 1$)$, the observed ecotoxicity results are in accordance with the documented ethoprophos $48-\mathrm{h} \mathrm{EC}_{50}$ of $200 \mu \mathrm{g} \mathrm{L}^{-1}$ for D. magna (EFSA, 2006). Given the measured pesticide concentration of $2200 \mu \mathrm{g} \mathrm{L}^{-1}$ in the elutriate from $\mathrm{R}$ area soil (Table 1 ), the observed $48-\mathrm{h} \mathrm{LC}_{50}$ of $10.6 \%$ corresponds to $233.2 \mu \mathrm{g} \mathrm{L}^{-1}$ (180$301 \mu \mathrm{g} \mathrm{L}^{-1}$ ), which is in agreement with the documented effect value for $D$. magna of $48-\mathrm{h} \mathrm{EC}_{50}=200 \mu \mathrm{g} \mathrm{L}^{-1}$ (EFSA, 2006).

\section{Conclusion}

The application of twice the recommended dosage of the insecticide ethoprophos, representing possible misuse under the simulation of crop-based scenarios (maize and potato) affected negatively the reproduction of terrestrial organisms exposed to soil, and reduced survival of aquatic invertebrates exposed to leachate and elutriates waters. Leachate proved to be an important transfer pathway of groundwater contamination by ethoprophos under realistic Mediterranean agricultural practices, as it resulted in the highest pesticide concentration in water samples from the maize and potato crop-based scenarios. Runoff was also considered as a relevant contamination pathway for the pesticide ethoprophos, although the observed toxic effects on the aquatic cladoceran from low pesticide concentrations were possibly due to other factors than those resulting from the pesticide use. Ethoprophos exposure in the potato crop scenario caused more toxic effects on non-target terrestrial and aquatic organisms than in the maize scenario at pesticide concentrations mimicking the recommended dosage and lower ( $1 / 2 \mathrm{RD})$. This may be expected since the application dosage in potato is 10 times higher than the dosage needed for treating maize crops against soil insects. The observed movement, associated with water flow during irrigation, transporting the pesticide from row areas where it was applied to the surrounding area, supports the idea that ethoprophos moved horizontally and possibly causing toxic effects on the surrounding terrestrial non-target communities. Moreover, the present study showed that groundwater may be at risk in irrigated agricultural fields with maize and potato crops and that terrestrial communities may be under threat when pesticide fate and effects are assessed using natural soil. Pesticides fate under field realistic environmental conditions and their toxicity on biota should be taken into account when conducting future work on their fate and effects to contribute to their sustainable use.

\section{Acknowledgments}

This study was partly sponsored by the European Fund for Economic and Regional Development (FEDER) through the Program Operational Factors of Competitiveness (COMPETE) and National Funds through the Portuguese Foundation of Science and Technology (Ph.D. grant to Sara Leitão - SFRH/BD/42306/2007, Ciência 2007 - POPH and QREN, and TerbAzineBiorem - PTDC/ AAC-AMB/111317/2009). We would like to thank all the colleagues at the Soil Ecology and Ecotoxicology Laboratory of the
Department of Life Sciences from Coimbra University for their knowledge and technical support of this study. The authors are also grateful to the anonymous reviewers for their reading of the manuscript, and for their suggestions and critical comments.

\section{Appendix A. Supporting information}

Supplementary data associated with this article can be found in the online version at http://dx.doi.org/10.1016/j.ecoenv.2014.01.029.

\section{References}

ASU L, 1999. Examination of Foodstuff - Modular Multi-Method for the Determination of Pesticides Residues in Foodstuff (Expanded Revision of the DFG-Method S 19) in Accordance with Section 64 of the German Food and Feed Code (LFGB) L-00.00-34. Technical Guideline.

Berenzen, N., Lentzen-Godding, A., Probst, M., Schulz, H., Schulz, R., Liess, M., 2005. A comparison of predicted and measured levels of runoff-related pesticide concentrations in small lowland streams on a landscape level. Chemosphere 58, 683-691.

Boesten, J.J.T.I., Gottesbüren, B., 2000. Testing PESTLA using two modellers for bentazone and ethoprophos in a sandy soil. Agric. Water Manag. 44, 283-305.

Boesten, J.J.T.I., Van der Pas, L.J.T., 2000. Movement of water, bromide and the pesticides ethoprophos and bentazone in a sandy soil: the Vredepeel data set. Agric. Water Manag. 44, 21-42.

Bouraoui, F., 2007. Testing the PEARL model in the Netherlands and Sweden. Environ. Model. Softw. 22, 937-950.

Certis, 2011. Safety Data (Insecticide MOCAP10G ${ }^{\mathbb{R}}$ ) 〈http:/www.certiseurope.co.uk/ fileadmin/downloads_uk/products/insecticides/MOCAP_10G_msds-1111.pdf) (last accessed: 6-06-2013).

Chelinho, S., Domene, X., Campana, P., Natal-da-Luz, T., Scheffczyk, A., Römbke, J., Andrés, P., Sousa, J.P., 2011. Improving ecological risk assessment in the Mediterranean area: selection of reference soils and evaluating the influence of soil properties on avoidance and reproduction of the Oligochaetes Eisenia andrei and Enchytraeus crypticus. Environ. Toxicol. Chem. 30 (5), 1050-1058.

Chelinho, S., Moreira-Santos, M., Silva, C., Costa, C., Viana, P., Viegas, C.A., Fialho, A. M., Ribeiro, R., Sousa, J.P., 2012. Semifield testing of a bioremediation tool for atrazine-contaminated soils: evaluating the efficacy on soil and aquatic compartments. Environ. Toxicol. Chem. 31 (7), 1564-1572.

Daam, M.A., Cerejeira, M.J., Van den Brink, P.J., Brock, T.C.M., 2011. Is it possible to extrapolate results of aquatic microcosm and mesocosm experiments with pesticides between climate zones in Europe? Environ. Sci. Pollut. R 18, 123-126.

Daphtoxkit Frm Magna, 2000. Crustacean Toxicity Screening Test for Freshwater. Standard Operational Procedure. MicroBioTests Inc., Nazareth, Belgium

De Silva, P.M.C.S., Pathiratne, A., van Gestel, C.A.M., 2009. Influence of temperature and soil type on the toxicity of three pesticides to Eisenia andrei. Chemosphere 76, 1410-1415.

DIN, 1984. German Standard Methods for the Examination of Water, Waste and Sludge - Sludge and Sediments, Determination of Leachability by Water. German Standard DIN 38 414-S4. Deutsches Institut für Normung, Berlin, Germany

DIN, 1993. German Standard Methods for the Determination of Water, Waste Water and Sludge; Jointly Determinable Substances (Group F); Determination of Low Volatile Halogenated Hydrocarbons by Gas Chromatography (F 2). German Standard DIN 38407-F2. Deutsches Institut für Normung, Berlin, Germany

Domene, X., Celinho, S., Campana, P., Natal-da-Luz, T., Alcañiz, J.M., Andrés, P., Römbke, J., Sousa, J.P., 2011. Influence of soil properties on the performance of Folsomia candida: implications for its use in soil ecotoxicology testing. Environ. Toxicol. Chem. 30 (7), 1497-1505.

Dowling, K.C., Costella, R.G., Lemley, A.T., 1994. Behaviour of the insecticides ethoprophos and carbofuran during soil-water transport. Pestic. Sci. 41, 27-33.

EC, 2000. European Commission, Guidance Document on Persistence in Soil. European Commission, Directorate General for Agriculture, DG VI-B.II-1, Working Document 9188/VI/97 rev. 8, 12.07.2000〈http:/ec.europa.eu/food/plant/ plant_protection_products/approval_active_substances/docs/wrkdoc11_en.pdf (last accessed: 07-11-2012).

ECR, 2009. European Commission Regulation, Concerning the Placing of Plant Protection Products on the Market and Repealing Council Directives 79/117/EEC and 91/ 414/EEC. Regulation (EC) No 1107/2009 of the European Parliament and of the Council of 21 October 2009, Official Journal of the European Union L 309/1.

EFSA, 2006. European Food Safety Authority. Conclusion on the Peer Review of the Pesticide Risk Assessment of the Active Substance Ethoprophos. EFSA Scientific Report 66, pp. 1-72.

EFSA, 2009. European Food Safety Authority. The usefulness of total concentrations and pore water concentrations of pesticides in soil as metrics for the assessment of ecotoxicological effects. EFSA J. 922, 1-90.

EuDASM, 2012. European Digital Archive Soil Maps. European Communities 19952011. European Commission - Joint Research Centre, Institute for Environment and Sustainability. 〈http:/eusoils.jrc.ec.europa.eu/library/maps/country_maps/ list_countries.cfm> (last accessed: 10-08-2012). 
FOOTPRINT, 2012. Pesticide Properties Database. Creating Tools for Pesticide Risk Assessment and Management in Europe. A Project Funded by the European Commission under the 6th Framework Programme. 〈http:/www.eu-footprint. org/> (last accessed: 10-08-2012).

Frampton, G.K., Jansch, S., Scott-Fordsmand, J.J., Rombke, J., Van den Brink, P.J., 2006. Effects of pesticides on soil invertebrates in laboratory studies: a review and analysis using species sensitivity distributions. Environ. Toxicol. Chem. 25 (9), 2480-2489.

Friberg-Jensen, U., Nachman, G., Christoffersen, K.S., 2010. Early signs of lethal effects in Daphnia magna (Branchiopoda, Cladocera) exposed to the insecticide cypermethrin and the fungicide azoxystrobin. Environ. Toxicol. 29, 1-8.

Gao, W., Smith, D.W., Li, Y., 2006. Natural freezing as a wastewater treatment method: E. coli inactivation capacity. Water Res. 40, 2321-2326.

Garratt, J.A., Capri, E., Trevisan, M., Errera, G., Wilkins, R.M., 2002. Parameterisation, evaluation and comparison of pesticide leaching models to data from a Bologna field site, Italy. Pest Manag. Sci. 58, 3-20.

Gustafson, D.I., 1989. Groundwater ubiquity score: a simple method for assessing pesticide leachability. Environ. Toxicol. Chem. 8, 339-357.

Gustafsson, K., Blidberg, E., Elfgren, I.K., Hellström, A., Kylin, H., Gorokhova, E., 2010. Direct and indirect effects of the fungicide azoxystrobin in outdoor brackish water microcosms. Ecotoxicology 19, 431-444.

Hamilton, M.A., Russo, R.C., Thurston, R.V., 1977. Trimmed Spearman-Karber method for estimating median lethal concentrations in toxicity bioassays. Environ. Sci. Technol. 11 (7), 714-719 (corr. 1978, 12 (4), 417).

ICNF, 2013. Instituto da Conservação da Natureza e das Florestas. Reserva Natural do Paul do Boquilobo. 〈http:/portal.icn.pt/ICNPortal/vPT2007-AP-PaulBoqui lobo (last accessed: 6-06-2013).

IM, 2010 Instituto de Meteorologia, IP de Portugal. 〈http:/www.meteo.pt/〉 (last accessed:10-04-2010).

ISO, 1994. Soil Quality -Determination of pH - Laboratory Methods. International Standard ISO 10390, International Organization for Standardization, Paris, France.

ISO, 1995. Soil Quality - Determination of Organic and Total Carbon after Dry Combustion (Elementary Analysis), International Standard ISO 10694, International Organization for Standardization, Geneva, Switzerland.

ISO, 1998. Soil Quality - Effects of Pollutants on Earthworms (Eisenia foetida). Part 2: Determination of Effects on Reproduction. International Standard ISO 11268-2.2, International Organization for Standardization, Geneva, Switzerland.

ISO, 1999. Soil Quality - Inhibition of Reproduction of Collembola (Folsomia candida) by soil. International Standard ISO 11267. International Organisation for Standardisation, Geneva, Switzerland.

ISO, 2000. Water Quality - Determination of Selected Organic Nitrogen and Phosphorus Compounds - Gas Chromatographic Methods. International Standard ISO 10695 International Organization for Standardization, Geneva, Switzerland.

ISO, 2004. Soil Quality - Effects of Pollutants on Enchytraeidae (Enchytraeus sp.) Determination of Effects on Reproduction and Survival. International Standard ISO 16387. International Organization for Standardization Geneva, Switzerland.

ISO, 2012. Water Quality. Determination of the Inhibition of the Mobility of Daphnia magna Straus (Cladocera, Crustacea). Acute Toxicity Test. International Standard ISO 6341. International Organization for Standardization. Brussels, Belgium.

Karpouzas, D.G., Walker, A., 2000. Aspects of the enhanced biodegradation and metabolism of ethoprophos in soil. Pest Manag. Sci. 56, 540-548.

Lavelle, P., Spain, A., 2001. Soil Ecology. Kluwer Academic Publishers, Dordrecht, The Netherlands

Lanno, R., Wells, J., Conder, J., Bradham, K., Basta, N., 2004. The bioavailability of chemicals in soil for earthworms. Ecotox. Environ. Safe. 57, 39-47.

Leitão, S., Cerejeira, M.J., Van den Brink, P., Sousa, J.P., 2014. Effects of azoxystrobin, chlorothalonil and ethoprophos on the reproduction of three terrestrial invertebrates using a natural Mediterranean soil. Appl. Soil Ecol. 76 (C) 124-131, http://dx.doi.org/10.1016/j.apsoil.2013.12.013.

MacBean, C., 2012. The Pesticide Manual, 16th Ed. BCPC, Hampshire

Mackay, D., 2001. Multimedia Environmental Models: the Fugacity Approach ('Level I, Version 3.00, 2004, Trentu University, Canada'), 2nd ed. Lewis Publishers, Boca Raton

Maltby, L., Blake, N., Brock, T.C.M., Van den Brink, P.J., 2005. Insecticide species sensitivity distributions: importance of test species selection and relevance to aquatic ecosystems. Environ. Toxicol. Chem. 24, 379-388.

OECD, 1998. Organisation for Economic Co-operation and Development. Daphnia Magna Reproduction Test. OECD Test Guidelines for Testing of Chemicals 211 Paris, France.

Pierzynski, G.M., Sims, J.T., Vance, G.F., 2000. Soils and Environmental Quality, 2nd Ed. CRC Press LLC, New York, United States of America

Pistocchi, A., 2010. On the temporal resolution of mass balance models for soluble chemicals in soils. Hydrol. Processes 24, 1172-1186.

Potter, D.A., Spicer, P.G., Redmond, C.T., Powell, A.J., 1994. Toxicity of pesticides to earthworms in Kentucky bluegrass turf. Bull. Environ. Contam. Toxicol. 52, $176-181$.

Robinson, D.E., Mansingh, A., Dasgupta, D.P., 1999. Fate and transport of ethoprophos in the Jamaican environment. Sci. Total Environ. 237/238, 373-378.

SANCO, 2002. European Commission Health \& Consumer Protection Directorate General, Directorate E - Food Safety: Plant Health, Animal Health and Welfare, International Questions, E1 - Plant Health. DRAFT Working Document Guidance Document on Terrestrial Ecotoxicology Under Council Directive 91/ 414/EEC. SANCO/10329/2002 rev 2 final.

Silva, E., Mendes, M.P., Ribeiro, L., Cerejeira, M.J., 2012a. Exposure assessment of pesticides in a shallow groundwater of the Tagus vulnerable zone (Portugal): a multivariate statistical approach (JCA). Environ. Sci. Pollut. R 19, 2667-2680.

Silva, E., Pereira, A.C., Estalagem, S.P., Moreira-Santos, M., Ribeiro, R., Cerejeira, M.J. 2012b. Assessing the quality of freshwaters in a protected area within the Tagus river basin district (central Portugal). J. Environ. Qual. 41, 1413-1426.

Smelt, J.H., Leistra, M., Voerman, S., 1977. Movement and rate of decomposition of ethoprophos in soil columns under field conditions. Pestic. Sci. 8, 147-151.

Sousa, J.P., Rodrigues, J.M.L., Loureiro, S., Soares, A.M.V.M., Jones, S.E., Forster, B., Van Gestel, C.A.M., 2004. Ring-testing and field-validation of a terrestrial mode ecosystem (TME) - an instrument for testing potentially harmful substances: effects of carbendazim on soil microbial parameters. Ecotoxicology 13 (1-2), 43-60.

Styrishave, B., Mortensen, M., Krogh, P.H., Andersen, O., Jensen, J., 2008. Solid-Phase Microextraction (SPME) as a tool to predict the bioavailability and toxicity of pyrene to the Springtail, Folsomia candida, under various soil conditions. Environ. Sci. Technol. 42, 1332-1336.

Tarazona, J.V., 2005. Geographical differences in the evaluation and prediction of effects of pesticides. In: Liess, M., Brown, C., Dohmen, P., Dequesne, S., Hart, A., Heimbach, F., et al. (Eds.), Effects of Pesticides in the Field. Ed.. SETAC, Berlin, pp. 102-104

Tiepo, E.N., Corrêa, A.X.R., Resgalla , C., Cotelle, S., Férard, J.-F., Radetski, C.M., 2010 Terrestrial short-term ecotoxicity of a green formicide. Ecotox. Environ. Safe. 73, 939-943.

Tiktak, A., 2000. Application of pesticide leaching models to the Vredepeel dataset II Pesticide fate. Agric. Water Manag. 44, 119-134.

Wang, Y., Wu, S., Chen, L., Wu, C., Yu, R., Wang, Q., Zhao, X., 2012. Toxicity assessment of 45 pesticides to the epigeic earthworm Eisenia fetida. Chemosphere $88,484-491$.

Warming, T.P., Mulderij, G., Christoffersen, K.S., 2009. Clonal variation in physiological responses of Daphnia magna to the strobilurin fungicide azoxystrobin. Environ. Toxicol. Chem. 28, 374-380. 